\title{
THERMAL PERFORMANCE OF A LOW-COST LOOP HEAT PIPE
}

\author{
Jentung Ku ${ }^{1}$, Hosei Nagano ${ }^{2}$, Jeffrey Perez ${ }^{3}$ \\ INASA Goddard Space Flight Center, Greenbelt, Maryland, USA \\ ${ }^{2}$ Keio University, Tokyo, Japan (NASA Visiting Researcher) \\ ${ }^{3}$ U.S. Army TARDEC, Warren, Michigan, USA
}

\begin{abstract}
This paper presents the thermal performance of a low-cost loop heat pipe (LHP) consisting of a single evaporator and a single condenser. The evaporator has an outer diameter of $14 \mathrm{~mm}$ and a length of $50 \mathrm{~mm}$. An organic solvent was used as the working fluid. The low-cost LHP was made possible through a new manufacturing process. The LHP demonstrated excellent performance over heat loads ranging from $1 \mathrm{~W}$ to $150 \mathrm{~W}$ and sink temperatures between $253 \mathrm{~K}$ and $293 \mathrm{~K}$. Tests performed included start-up, power cycle, sink temperature cycle, high power and low power operations. No performance anomalies were seen.
\end{abstract}

\section{Introduction}

A loop heat pipe (LHP) is a versatile two-phase heat transfer device that can transport large heat loads over long distances with small temperature differences [1, 2]. LHPs have been used for thermal control of several commercial communications satellites and NASA spacecraft including ICESAT, SWIFT, AURA and GOES [3-6]. The application of LHPs is currently restricted to space and some special areas due to their high manufacturing costs. Recently, NASA Goddard Space Flight Center and the U.S. Army have purchased a low-cost LHP and jointly conducted a test program. The LHP demonstrated excellent performance over heat loads ranging from $1 \mathrm{~W}$ to $150 \mathrm{~W}$ and sink temperatures between $243 \mathrm{~K}$ and $293 \mathrm{~K}$. Tests performed included start-up, power cycle, sink temperature cycle, high power and low power operations. No performance anomalies were seen. The low-cost LHP was made possible because of a new manufacturing process employed by the vendor. Thus, the LHP has the potential to become the next-generation heat transfer device to cool terrestrial devices such as advanced electronics which have high power dissipations.

In this paper, important design parameters of the LHP, and the test set-up for performance testing will be described first. This will be followed by detailed descriptions of the tests conducted and the experimental results.

\section{Test Article and Test Set-up}

The low-cost LHP that was tested has a single evaporator and a single condenser. The evaporator and its integral compensation chamber (CC) have an outer diameter (O.D.) of 14mm and lengths of $50 \mathrm{~mm}$ and $40 \mathrm{~mm}$, respectively. The primary wick has a pore radius of $2.5 \mu \mathrm{m}$. The vapor line, liquid line, and condenser have an O.D. of $4 \mathrm{~mm}$ and lengths of $100 \mathrm{~mm}, 233 \mathrm{~mm}$ and $625 \mathrm{~mm}$, respectively. An organic solvent is used as the working fluid. Additional design parameters can be found in Table 1. A picture of the test article is shown in Figure 1.

An aluminium saddle was attached to the evaporator and a cartridge heater was inserted into the aluminium saddle to provide heat loads up to $150 \mathrm{~W}$. The condenser was attached to a cold plate that was cooled by a circulating coolant provided by a refrigerator. Forty type- $T$ thermocouples were used to monitor the temperatures. A data acquisition system consisting of a data logger, a personal 
computer, and a monitor was used to display and store the temperature data as frequently as every second. A schematic of the test article with thermocouple locations is given in Figure 2.

Table 1. Low-Cost LHP Design Parameters

\begin{tabular}{|l|l|r|}
\hline \multicolumn{2}{|c|}{ Design Parameter } & Value \\
\hline Evaporator & O. D. & $14.0 \mathrm{~mm}$ \\
\cline { 2 - 3 } & I. D. & $13.0 \mathrm{~mm}$ \\
\cline { 2 - 3 } & Length & $50.0 \mathrm{~mm}$ \\
\hline \multirow{4}{*}{ Primary } & O. D. & $13.0 \mathrm{~mm}$ \\
\cline { 2 - 3 } & I. D. & $5.0 \mathrm{~mm}$ \\
\cline { 2 - 3 } & Length & $40.0 \mathrm{~mm}$ \\
\cline { 2 - 3 } & Pore Radius & $2.5 \mu \mathrm{m}$ \\
\cline { 2 - 3 } & Permeability & $4.5 \times 10^{-13} \mathrm{~m}^{2}$ \\
\hline CC & O. D. & $14.0 \mathrm{~mm}$ \\
\cline { 2 - 3 } & I..D. & $13.0 \mathrm{~mm}$ \\
\cline { 2 - 3 } & Length & $40.0 \mathrm{~mm}$ \\
\hline Vapor line & O. D. & $4.0 \mathrm{~mm}$ \\
\cline { 2 - 3 } & I.D. & $2.8 \mathrm{~mm}$ \\
\cline { 2 - 3 } & Length & $100 \mathrm{~mm}$ \\
\hline \multirow{5}{*}{ Liquid line } & O. D. & $4.0 \mathrm{~mm}$ \\
\cline { 2 - 3 } & I.. D. & $2.8 \mathrm{~mm}$ \\
\cline { 2 - 3 } & Length & $233 \mathrm{~mm}$ \\
\hline Condenser & O. D. & $4.0 \mathrm{~mm}$ \\
\cline { 2 - 3 } & I. D. & $2.8 \mathrm{~mm}$ \\
\cline { 2 - 3 } & Length & $625 \mathrm{~mm}$ \\
\hline \multirow{5}{*}{$\begin{array}{l}\text { Working } \\
\text { fluid }\end{array}$} & Material & Organic solvent \\
\cline { 2 - 3 } & Inventory & $11 \mathrm{grams}$ \\
\hline
\end{tabular}

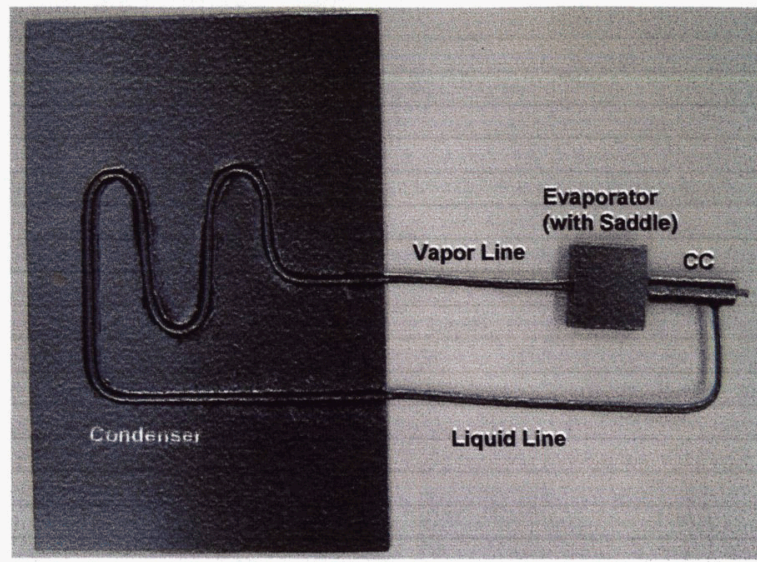

Figure 1 Picture of Low-Cost LHP

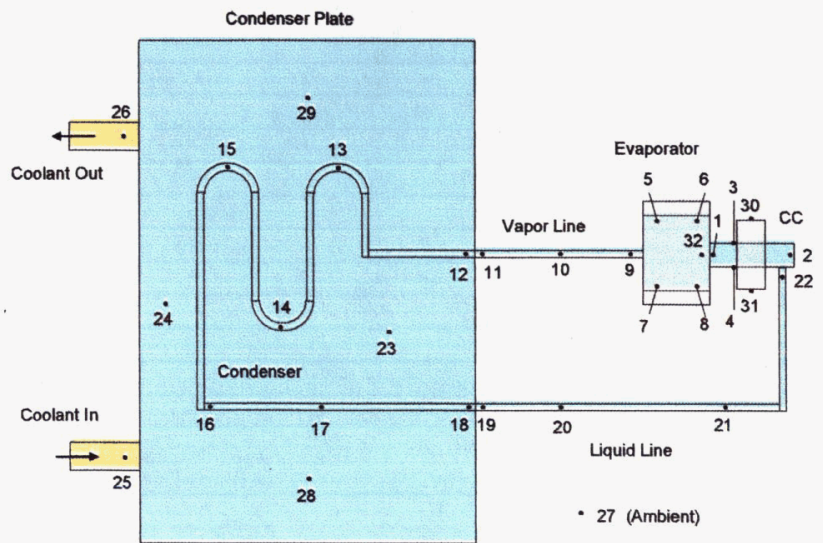

Figure 2 Schematic of Low-Cost LHP with

Thermocouple Locations

\section{Tests and Results}

The purpose of this test program was to characterize the performance of the low-cost LHP under various operating conditions. Characterization tests conducted included start-up, power cycle, sink temperature cycle, high power, and low power operations. All tests were conducted with the LHP in a horizontal plane. Descriptions of each test follow.

\section{Start-up Test}

An LHP must start successfully before it can transport a heat load. Start-up can be problematic in some cases and may require pre-conditioning, especially at low heat loads $[1,2]$. Start-up tests for the low-cost LHP were conducted under various heat loads and sink temperatures. The LHP started successfully in all cases by simply applying a heat load to the evaporator without any preconditioning. The evaporator heat load ranged from $1 \mathrm{~W}$ to $50 \mathrm{~W}$, and the condenser sink temperature varied between $243 \mathrm{~K}$ and $293 \mathrm{~K}$. The start-up is characterized by an increase of the vapor line temperature to the $\mathrm{CC}$ saturation temperature and a decrease of the liquid line temperature, indicating that a flow circulation has been established. Start-up is successful if the flow circulation continues and the $\mathrm{CC}$ and the evaporator temperatures are steady, with the evaporator temperature slightly higher than that of the $\mathrm{CC}$. 
Thirty-two start-up testes were conducted and all were successful. Figures 3 shows the temperature profiles during the start-up where $5 \mathrm{~W}$ was applied to the evaporator at a condenser sink temperature of $253 \mathrm{~K}$. The vapour line temperature rose to the saturation temperature minutes after $5 \mathrm{~W}$ was applied, and the loop reached a steady state quickly. At 10:05, the heat load increased to $100 \mathrm{~W}$, and the loop operated at a different temperature.

Figure 4 shows the temperature profiles for a start-up with $50 \mathrm{~W}$ to the evaporator and the condenser temperature was maintained at $263 \mathrm{~K}$. At such a high power, the loop started almost immediately. The loop reached a steady state after a very short transient period.

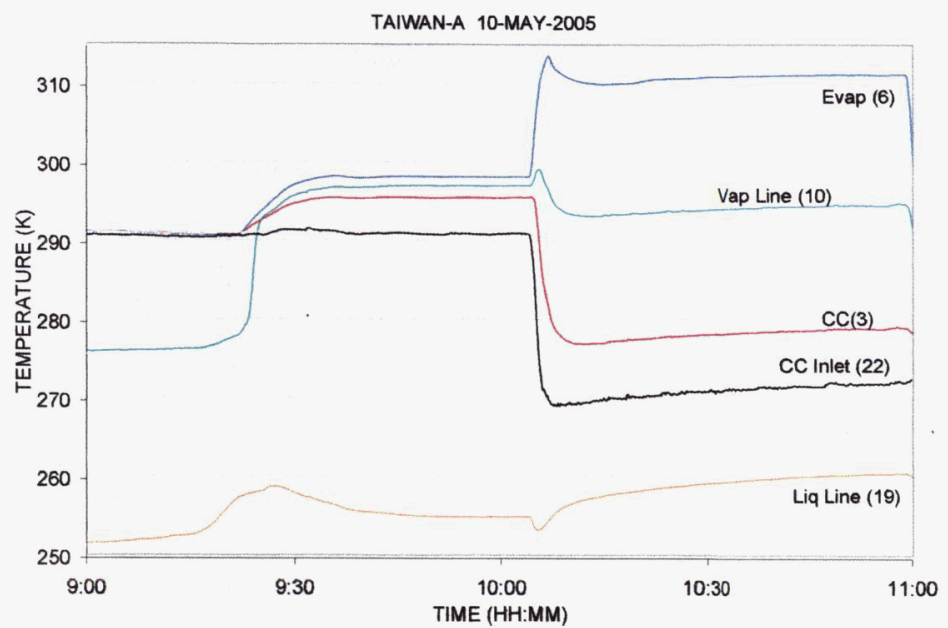

Figure 3. Start-up with $5 \mathrm{~W}$ at Condenser Sink of $253 \mathrm{~K}$ (need to add power)

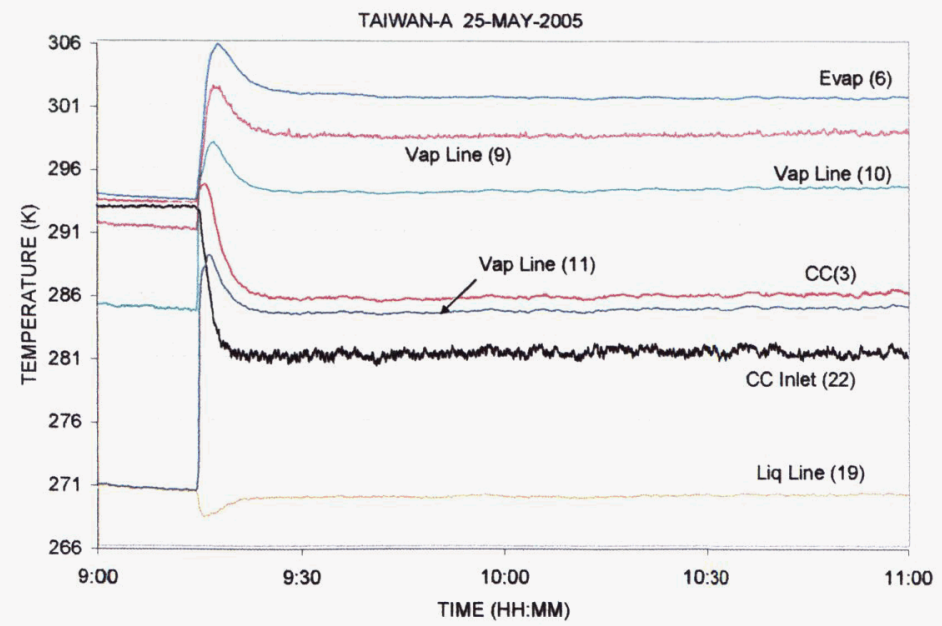

Figure 4. Start-up with $50 \mathrm{~W}$ at Condenser Sink of $263 \mathrm{~K}$

\section{Power Cycle Test}

The power cycle test was performed by imposing a sudden, large step change in the evaporator heat load. The purpose of this test was to verify that the LHP could adapt to a rapid change in the heat load, especially during the power step down. Typical power cycle tests performed included power profiles of $5 \mathrm{~W} / 100 \mathrm{~W} / 5 \mathrm{~W}, 50 \mathrm{~W} / 2.5 \mathrm{~W} / 50 \mathrm{~W}$, and $100 \mathrm{~W} / 2.5 \mathrm{~W} / 25 \mathrm{~W}$ at sink temperatures ranging from $253 \mathrm{~K}$ to $293 \mathrm{~K}$. 
Figure 5 shows the temperature profiles during a power cycle test where the heat load varied between $100 \mathrm{~W}$ and $5 \mathrm{~W}$ at a sink temperature of $263 \mathrm{~K}$. The corresponding power turn down ration was 20. The $\mathrm{CC}$ temperature varied with the heat load as expected. Also note that the loop reached a steady state much quicker at $100 \mathrm{~W}$ than at $5 \mathrm{~W}$. Figure 6 shows the temperature profiles in another power cycle test with heat load varying between $25 \mathrm{~W}$ and $2.5 \mathrm{~W}$ while the sink temperature was kept constant at $273 \mathrm{~K}$.

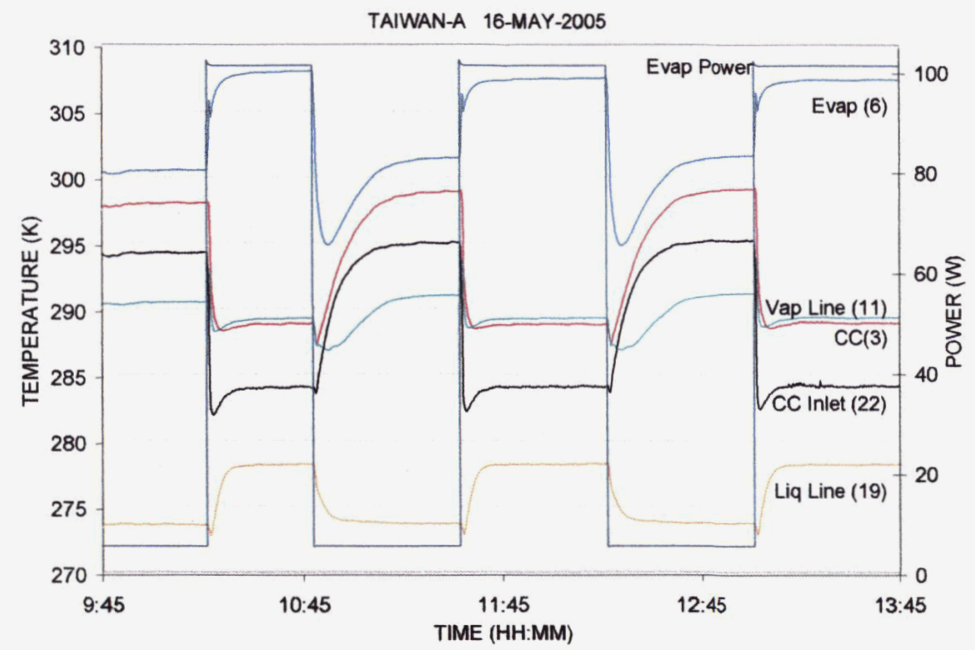

Figure 5. Power Cycle Test of 5W/100W/5W at Condenser Sink of $263 \mathrm{~K}$

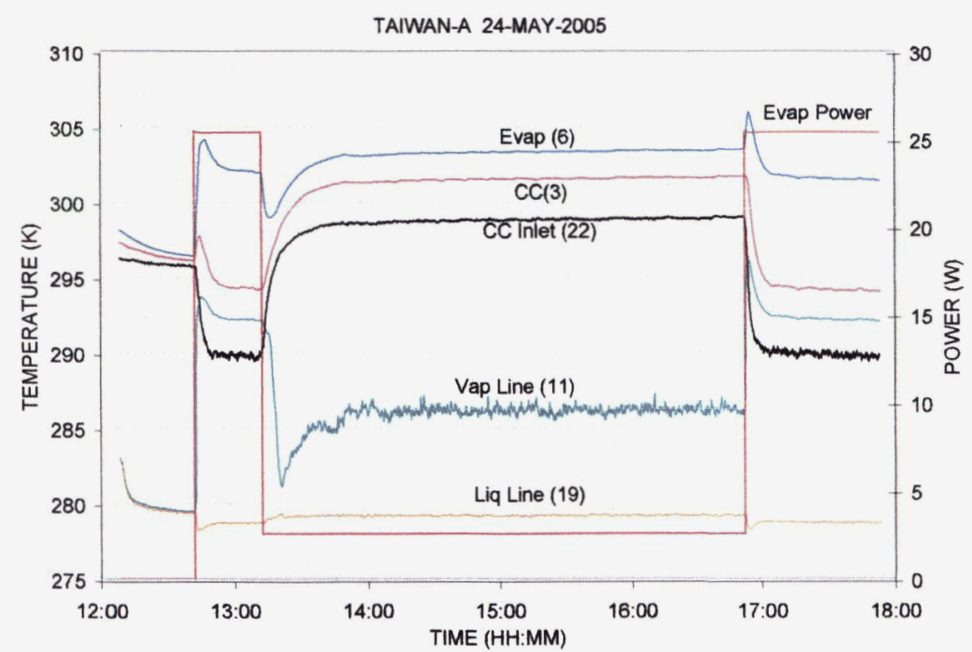

Figure 6. Power Cycle Test of $2.5 \mathrm{~W} / 25 \mathrm{~W} / 2.5 \mathrm{~W}$ at Condenser Sink of $273 \mathrm{~K}$

\section{Sink Temperature Cycle Test}

The sink temperature cycle test was conducted by making a sudden and large change in the condenser sink temperature. The purpose of this test was to verify that the LHP could adapt to a rapid sink temperature change. A typical sink temperature cycle test included a sink temperature profile such as $243 \mathrm{~K} / 273 \mathrm{~K} / 293 \mathrm{~K} / 243 \mathrm{~K} 293 \mathrm{~K} / 273 \mathrm{~K}$, and the evaporator heat load was kept constant at $5 \mathrm{~W}, 25 \mathrm{~W}$ or $50 \mathrm{~W}$. The LHP demonstrated successful operation in all tests, i.e. the loop reached a new steady state after a short period of transient following the sink temperature change. 
Figure 7 shows the temperature profile in a sink temperature cycle test where the evaporator heat load was kept constant at $50 \mathrm{~W}$ and the condenser sink temperature varied between $243 \mathrm{~K}$ and $293 \mathrm{~K}$. The loop operating temperature varied with the sink temperature as expected. Figure 8 illustrates another sink temperature cycle test at a heat load of $5 \mathrm{~W}$. Note that at low heat loads, the condenser was hardly utilized and the $\mathrm{CC}$ temperature was dependent more upon the ambient temperature than the sink temperature.

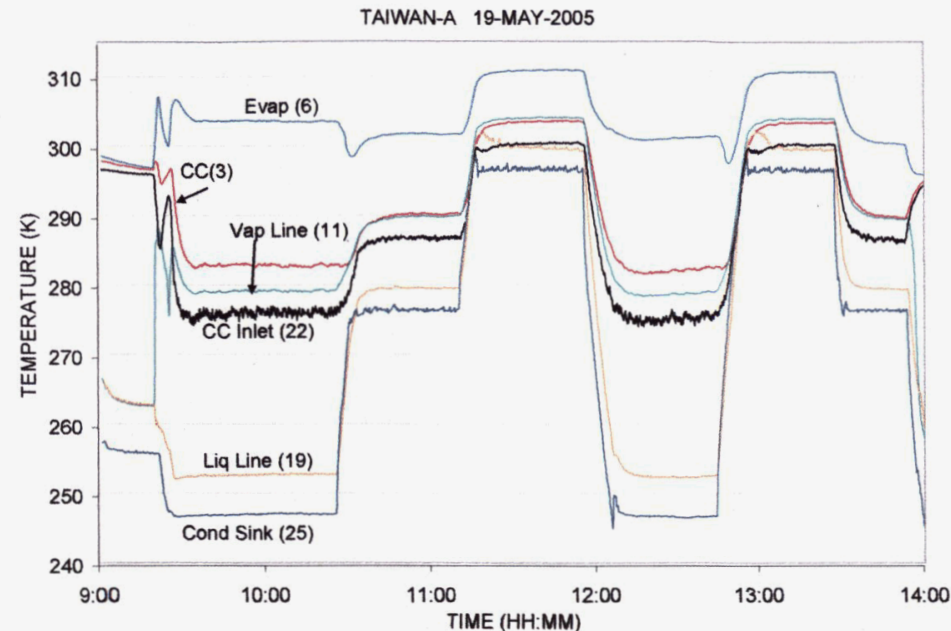

Figure 7. Sink Temperature Cycle Test at 50W

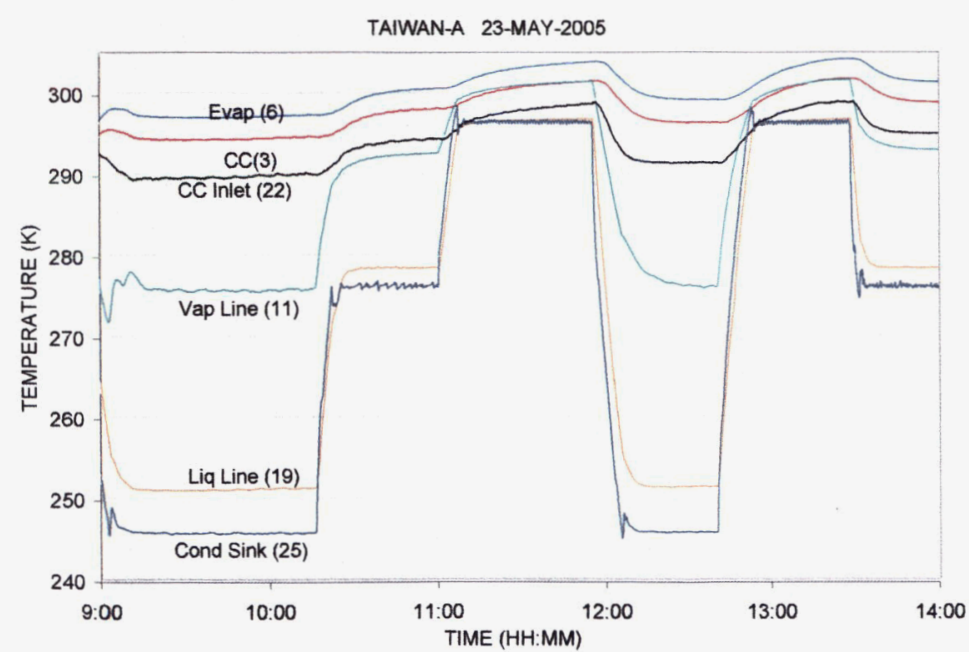

Figure 8. Sink Temperature Cycle Test at $5 \mathrm{~W}$

Figure 9 shows the loop temperature profiles in a test where an evaporator heat load change was superimposed upon the sink temperature change, i.e. the power was varied between $25 \mathrm{~W}$ and $100 \mathrm{~W}$ while the sink temperature changed between $253 \mathrm{~K}$ and $293 \mathrm{~K}$. Again, the loop demonstrated its ability to adopt to simultaneous changes of the heat load and the condenser sink temperature and operated successfully. 


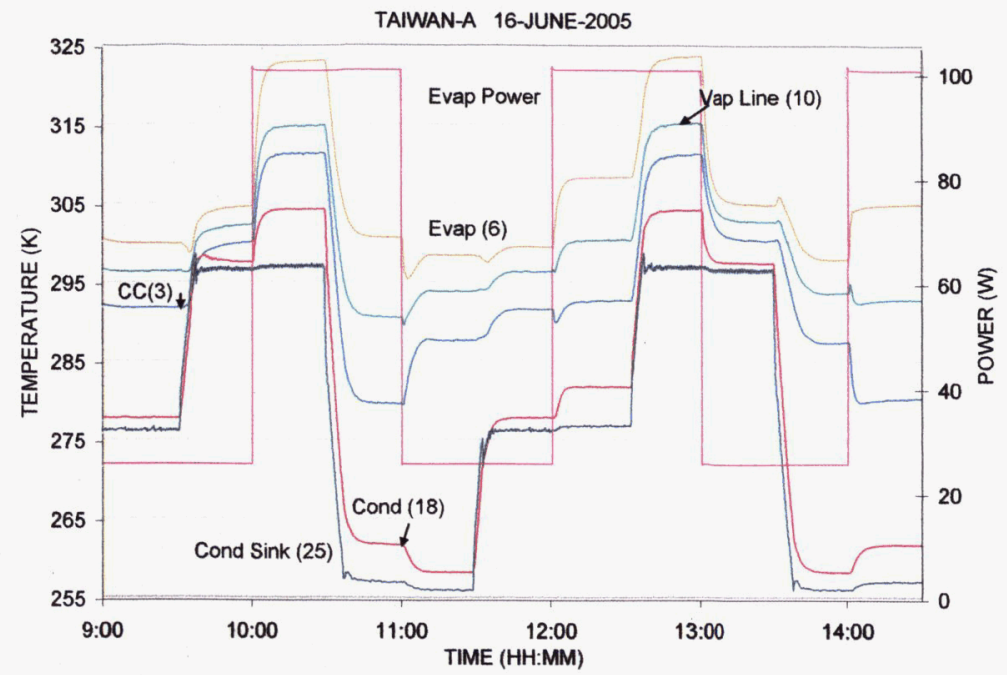

Figure 9. Power Cycle and Sink Temperature Cycle Test

\section{$\underline{\text { High Power Test }}$}

The high power test was conducted following a successful start-up by gradually increasing the heat load in steps until the evaporator capillary limit was reached. When the evaporator capillary limit is reached, the $\mathrm{CC}$ temperature will increase sharply, and so does the difference between the evaporator temperature and the $\mathrm{CC}$ temperature due to a penetration of the vapor through the primary wick. Under most circumstances, the loop will reach a new steady state at a higher CC temperature, and the loop will return to normal operation as the heat load is reduced. However, a temperature excursion may result when the applied heat far exceed the loop's heat transport limit.

Figure 10 shows that the loop reached the capillary limit at $140 \mathrm{~W}$. Nevertheless, the loop reached a new steady state even when the heat load was further increased to $150 \mathrm{~W}$. The evaporator recovered from a dry-out as soon as the heat load was reduced to $70 \mathrm{~W}$.

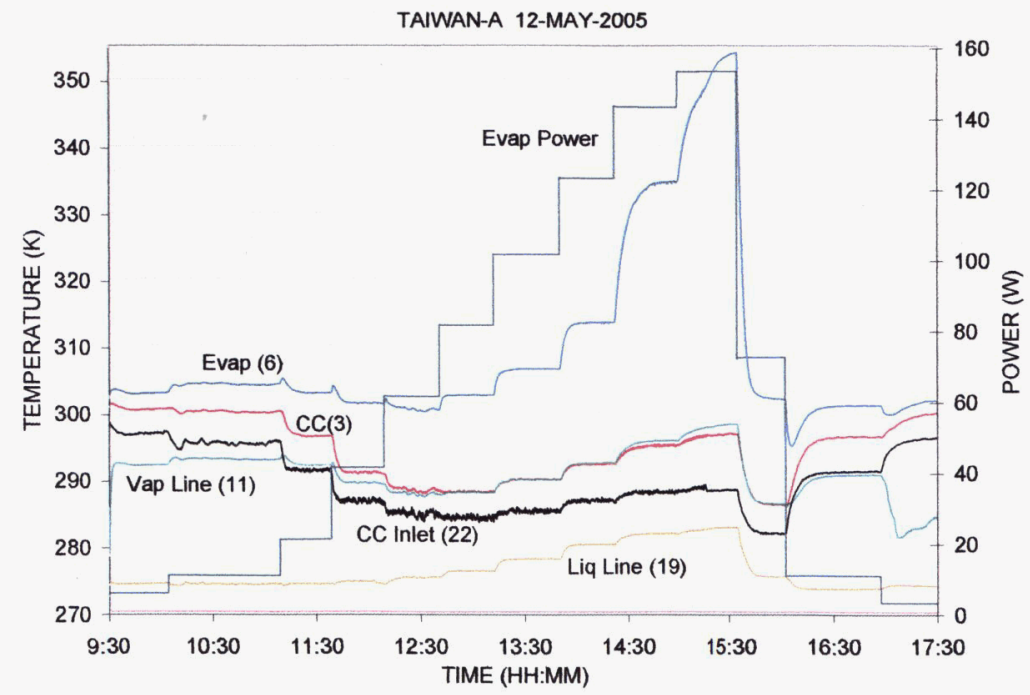

Figure 10 Temperature Profiles During a High Power Test at 273K Sink 
Figure 11 shows another high power test at a sink temperature of $293 \mathrm{~K}$. The evaporator and the CC temperatures rose sharply as the heat load exceeded $150 \mathrm{~W}$, but recovered as the heat load was decreased to $100 \mathrm{~W}$.

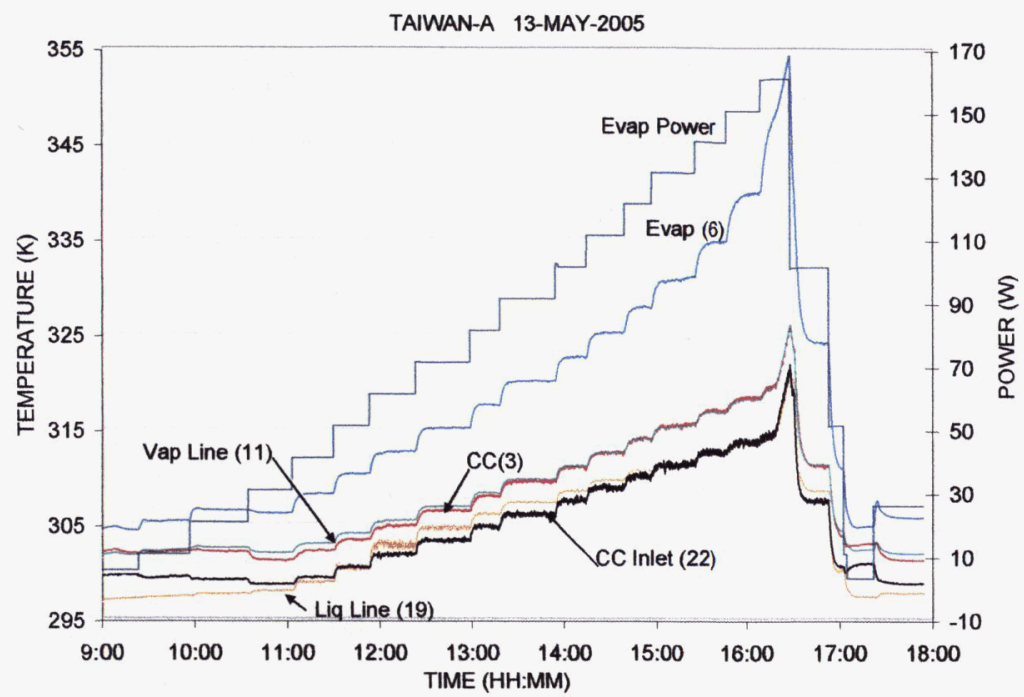

Figure 11 Temperature Profiles During a High Power Test at 293K Sink

\section{$\underline{\text { Low Power Test }}$}

The flow circulation in an LHP is very slow at low powers, and is near stagnation at extreme low powers. The low heat load represents another challenge on the LHP operation. In the low power range, the operating temperature tends to increase with a decreasing heat load in order for the returning liquid to provide enough subcooling to compensate for the heat leak from the evaporator to the CC.

Figure 12 shows the loop operated at $5 \mathrm{~W}$ for 8 hours. At this low power, the CC temperature was mainly a function of the ambient temperature. Test results show that the $\mathrm{CC}$ temperature increased by $0.5 \mathrm{~K}$ over the test period. This was caused by a steady increase of the ambient temperature from $298 \mathrm{~K}$ to $299 \mathrm{~K}$ over the same period. Figure 13 shows that the loop could operate at heat loads as low as $1 \mathrm{~W}$ and $0.5 \mathrm{~W}$. The loop operation at these low powers was evidenced by the fact that the CC temperature varied with the heat load and that the vapor line temperature rose and fell in tandem with the CC temperature.

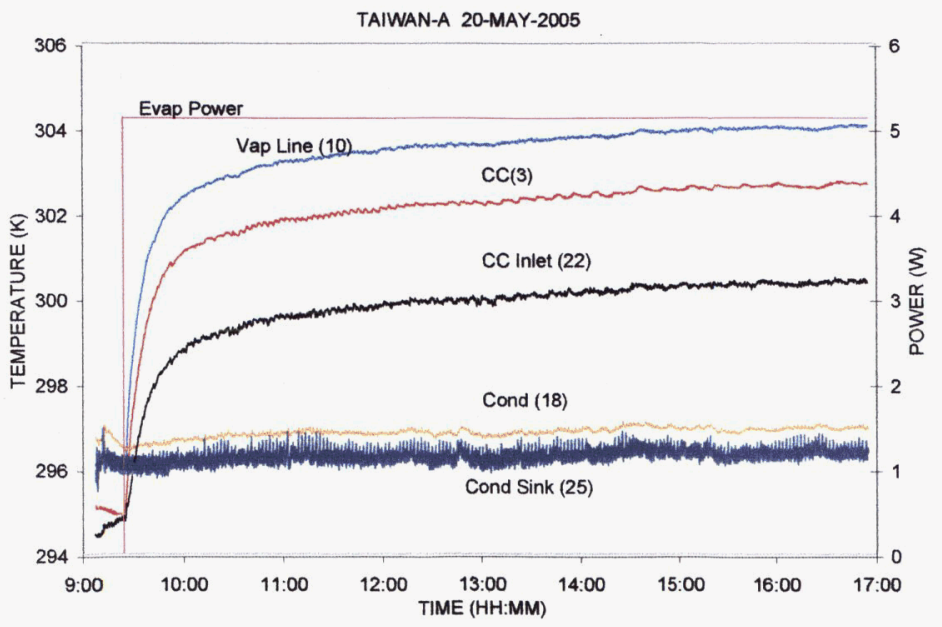

Figure 12 Temperature Profile During a Low Power Test 


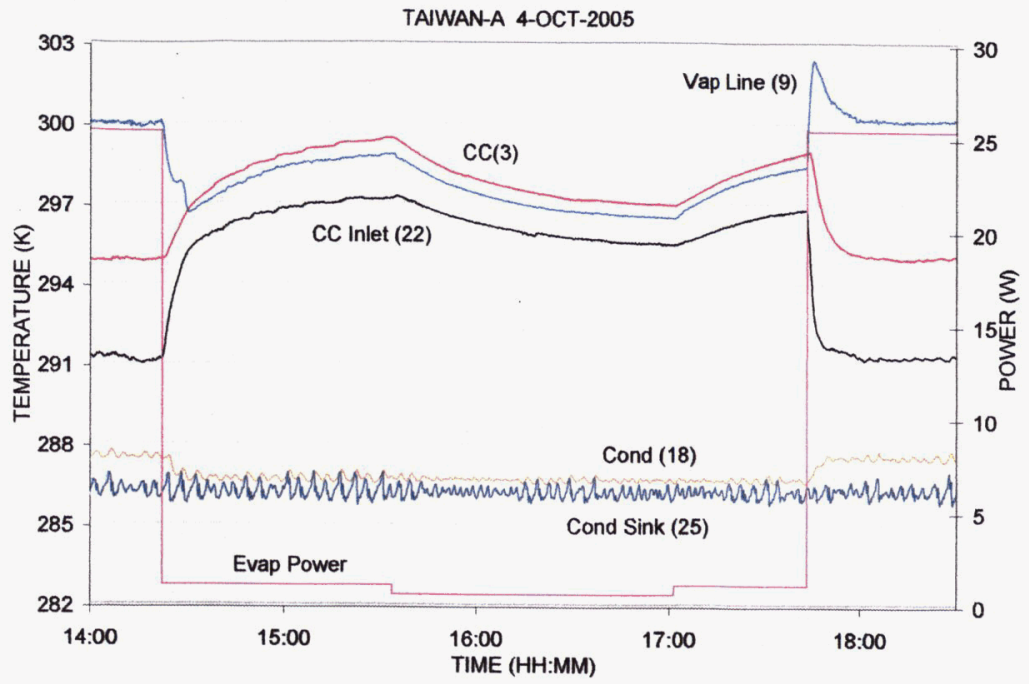

Figure 13 Temperature Profile during a Low Power Test

\section{Characteristic Operating Temperature Curve}

Figure 10 shows that the CC temperature decreased with an increasing heat load, reached a minimum and then increased with an increasing heat load. This is characteristic of the LHP operation when the ambient temperature is higher than the condenser sink temperature. The ambient temperature for all tests was between $292 \mathrm{~K}$ and $298 \mathrm{~K}$. For all heat transport tests performed at sink temperatures of $253 \mathrm{~K}, 273 \mathrm{~K}$ and $283 \mathrm{~K}$, the same operating characteristics were seen. Figure 11, on the other hand, shows that the $\mathrm{CC}$ temperature increased with the heat load at all powers. This was because the sink temperature was at $293 \mathrm{~K}$, the same as the ambient temperature.

Figure 14 depicts the $\mathrm{CC}$ temperature as a function of the heat load at various sink temperatures. The plots yield the well known "V-shaped" curves. The minimum CC temperature in Figure 14 corresponds to the minimum heat load at which the condenser is fully utilized for vapor condensation. The heat load at which the minimum $\mathrm{CC}$ temperature occurred increased with a decreasing sink temperature, i.e. the condenser could accommodate a higher heat load at a lower sink temperature before it was fully utilized.

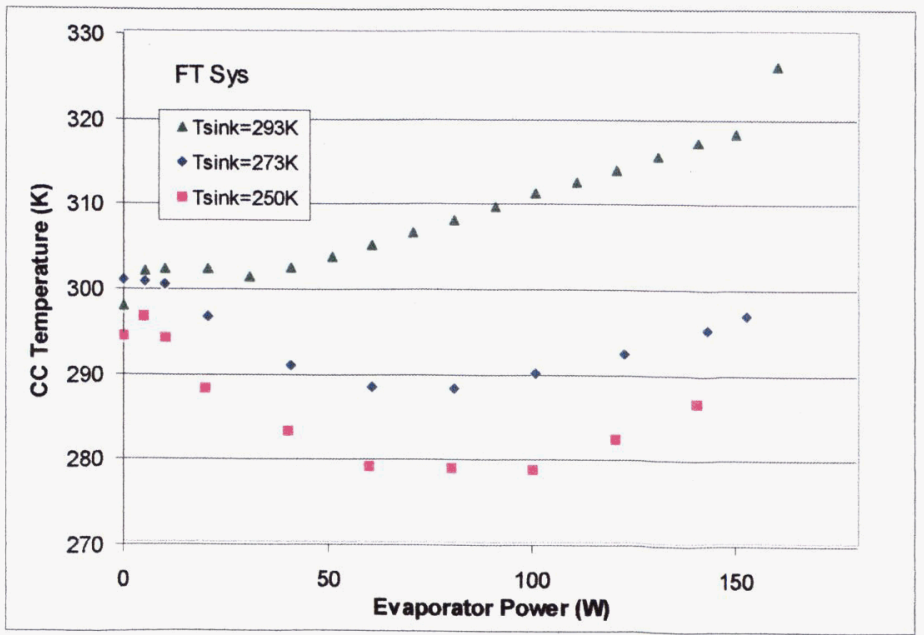

Figure 14 Loop Operating Temperature versus Heat Load 
The CC temperature is directly affected by the condenser temperature, which in turn is a function of the condenser sink environment. As the condenser environment changes, e.g. from a convective environment to a radiative environment, the condenser temperature will be different, and so will the $\mathrm{CC}$ temperature. For the same reason, when the chiller which provides the circulating coolant to the condenser changes, the $\mathrm{CC}$ temperature could be affected. During the course of this test, two chillers were used because the first chiller malfunctioned shortly after test program began. Figure 15 shows how the loop operating temperature changed with the chiller at all power levels.

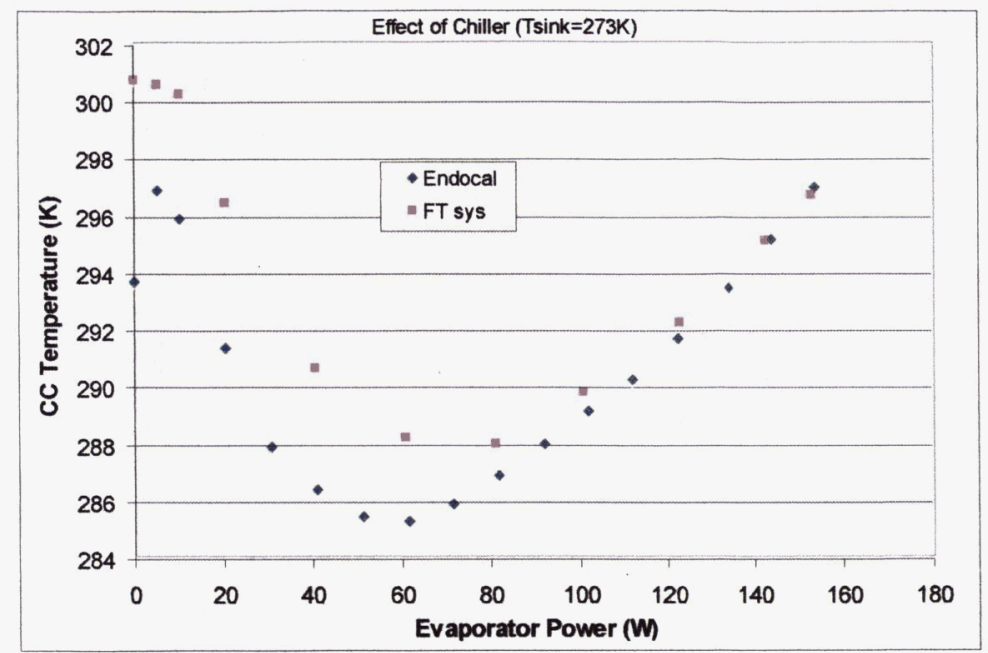

Figure 15 Effect of Different Sinks on the Loop Operating Temperature

\section{Summary and Conclusion}

A low-cost LHP was tested for performance characterization. The LHP demonstrated excellent performance over a wide range of operating conditions. Tests conducted included start-up, high power, low power, rapid power change and rapid sink temperature change. The loop could start with heat loads between $1 \mathrm{~W}$ and $50 \mathrm{~W}$. It demonstrated stable operation with the heat load ranging from $1 \mathrm{~W}$ to $150 \mathrm{~W}$, and the condenser sink temperature from $243 \mathrm{~K}$ to $293 \mathrm{~K}$. The loop could adapt to step changes of the evaporator heat load from $5 \mathrm{~W}$ to $100 \mathrm{~W}$ to $2.5 \mathrm{~W}$, and step changes of the sink temperature between $243 \mathrm{~K}$ and $293 \mathrm{~K}$. The loop operating temperature versus the heat load followed the typical "V-shaped" curve for a given condenser sink temperature. No performance anomalies were seen. Thus, the low-cost LHP has the potential to become the next-generation heat transfer device to cool terrestrial devices such as advanced electronics which have high power dissipations.

\section{References}

1. Maidanik, Y., and Y. Fershtater, "Theoretical Basis and Classification of Loop Heat Pipes and Capillary Pumped Loops," $10^{\text {th }}$ International Heat Pipe Conference, Stuttgart, Germany, 1997.

2. Ku, J., "Operating Characteristics of Loop Heat Pipes," SAE Paper No. 1999-01-2007.

3. Baker, C., Butler, D., Ku, J., and E. Grob, "Acceptance Thermal Vacuum Tests of the GLAS Flight Loop Heat Pipe Systems," STAIF 2001, American Institute of Physics, Albuquerque, New Mexico, February 11-14, 2001.

4. Baker, Grob, E., "System Accommodation of Propylene Loop Heat Pipes for The Geoscience Laser Altimeter System (GLAS) Instrument," SAE paper No. 2001-01-2263, 2001.

5. Ottenstein, L., Ku, J., and D. Feenan, "Thermal Vacuum Testing of a Novel Loop Heat Pipe Design for the Swift BAT Instrument," Space Technology and Applications International Forum -2003, February 2-6, 2003, Albuquerque, New Mexico. 
6. Choi, M., "Thermal Vacuum/Balance Test Results of Swift BAT with Loop Heat Pipe Thermal System", AIAA Paper No. 2004-5683, $2^{\text {nd }}$ IECEC, Providence, Rhode Island, August 16-19, 2004. 